\title{
Clinical severity of atopic dermatitis is associated with dental caries risk in 3-year old children
}

\author{
Tosha Ashish Kalhan ${ }^{1}$, Evelyn Loo ${ }^{2}$, Lynette Shek ${ }^{1}$, Michael Kramer ${ }^{3}$, Carolina Un Lam ${ }^{4}$, \\ Bindu Karunakaran ${ }^{1}$, Hugo Van Bever ${ }^{1}$, Anne Goh ${ }^{5}$, Yap Chong ${ }^{6}$, bee wah lee ${ }^{1}$, Kok Hian \\ Tan $^{7}$, Seang Saw $^{6}$, Keith Godfrey ${ }^{8}$, and Chin-Ying Hsu ${ }^{1}$ \\ ${ }^{1}$ National University of Singapore \\ ${ }^{2}$ Singapore Institute for Clinical Sciences (SICS), Agency for Science, Technology and \\ Research (A*STAR),Singapore \\ ${ }^{3}$ McGill University Faculty of Medicine \\ ${ }^{4}$ Ministry of Health Holdings Pte Ltd \\ ${ }^{5} \mathrm{KK}$ Women's and Children's Hospital \\ ${ }^{6} \mathrm{NUHS}$ \\ ${ }^{7}$ Department of Maternal Fetal Medicine, KK Women's and Children's Hospital (KKH) \\ ${ }^{8}$ University of Southampton
}

December 9, 2020

\begin{abstract}
Background: Infants with atopic dermatitis (AD) are reported to be at higher risk of early childhood caries (ECC) at 3-years, but the clinical validity of the reported link remains unknown. We investigated if clinical severity of AD in young children is associated with increased ECC risk at 3-years. Methods: In Growing Up in Singapore Towards healthy Outcomes (GUSTO) mother-offspring cohort, AD was diagnosed by trained physicians using Hanifin and Rajka criteria at 18-month and 3-year clinic visits $(\mathrm{n}=837)$. Of the children diagnosed with AD, disease severity was assessed using SCORAD (SCORing Atopic Dermatitis) index and categorized into moderate-to-severe AD (SCORAD[?]25), and mild AD (SCORAD $<25)$, with children without AD (non-AD) as a reference group. Oral examinations for ECC detection was performed by calibrated dentists in 656 children at age 3-years. Negative binomial regression was used to calculate the adjusted incidence risk ratio (aIRR; adjusted for socio-demographic factors and prenatal tobacco smoke exposure). Results: Atopic dermatitis was diagnosed in 7.3\% (61/837) children; amongst which $23 \%$ had moderate-to-severe AD and $77 \%$ had mild AD. ECC was observed in $85.7 \%, 36.8 \%$ and $42.8 \%$ of the children in moderate-to-severe, mild and non-AD groups, respectively. Children with moderate-to-severe AD were at higher risk of ECC (aIRR 2.30 [95\% confidence interval (CI) 1.04-5.06]; $\mathrm{p}=0.03$ ) at 3 years compared to non-AD, while no association was seen between mild AD and ECC. Conclusions: Children with moderate-to-severe atopic dermatitis were at higher risk of ECC compared to those without AD and may benefit from early dental referral.
\end{abstract}

\section{Introduction}

Atopic dermatitis $(\mathrm{AD})$ is a chronic relapsing inflammatory skin disease with peak incidence in the first 2 years of life ${ }^{1}$. It affects approximately 8.4 million children ( $<18$ years) in the US, with 1 in 3 AD cases exhibiting moderate to severe forms of disease ${ }^{2}$. Moreover, children with severe AD exhibit lower quality of life ${ }^{3}$ and higher risk of comorbid chronic health conditions, such as asthma and allergic rhinitis, compared to mild $\mathrm{AD}$, in addition to a two-fold higher healthcare utilization ${ }^{4}$. Early childhood caries (ECC), a chronic diet-mediated oral infectious disease, affecting approximately 12.4 million children $(<18 \text { years })^{5}$, is ranked 
fifth amongst the top 30 global health conditions in terms of incidence rates ${ }^{6}$. Although two large-scale crosssectional studies in 0-17 year old American $(\mathrm{N}=79,667)^{4}$ and $6-15$ year old Japanese children $(\mathrm{N}=21,792)^{7}$ reported no association between allergic diseases (including AD) and dental caries, our previous study using a longitudinal study design revealed a potential link with higher ECC risk at 2- and 3-years in infants with atopic dermatitis ${ }^{8}$. However, validity of the diagnostic criteria employed previously and effect of clinical severity on the AD-ECC link remains unknown.

Large-scale population studies often employ caregiver-reported 1-year history of a doctor-diagnosed AD as a proxy measure to estimate $\mathrm{AD}$ prevalence in children ${ }^{9}$, which has been reported to render low sensitivity (70\%) in identifying AD in 0-17 year old children ${ }^{10}$. As more than two-thirds of infants with moderateto-severe forms of $\mathrm{AD}$ demonstrate allergic sensitization in the first 2 years of life ${ }^{11}$, our previous study supplemented the caregiver-reported history with a positive skin prick test (SPT) for identification of AD 8. Nevertheless, use of SPT in AD diagnosis has not been validated yet. Furthermore, children with severe $\mathrm{AD}$ have been associated with poor oral hygiene/dietary control possibly due to a distraction by symptoms and management of $\mathrm{AD}^{12}$; however the regression model testing the previous AD-ECC link did not account for these behavioural factors. Hence, the current study aimed to investigate if clinical severity of AD by 3 years is associated with increased ECC risk among 3-year old children with/without control of potential dietary/behavioural confounders. Additionally, diagnostic accuracy of caregiver-reported history of doctordiagnosed $\mathrm{AD}$, with/without SPT, was evaluated using physician diagnosis as the gold standard.

\section{Methods}

Study design and data collection

A schematic illustration of study design is presented in Figure 1. Ethical approval was obtained from Centralized Institutional Review Board (CIRB) of SingHealth (reference 2009/280/D) and Domain Specific Review Board (DSRB) of Singapore National Healthcare Group (reference D/09/021). The Growing Up in Singapore Towards healthy Outcomes (GUSTO) cohort is a mother-offspring birth cohort where only Singapore citizens or permanent residents of Chinese, Malay and Indian ethnicity with homogenous ethnic background were approached for participation ${ }^{13}$. A total of 1247 healthy pregnant women, aged 18 years and above, were recruited during their first trimester ( $<14$ weeks' gestation) at two major public maternity hospitals in Singapore. Interviewer-administered questionnaires were used at 26-28 weeks of gestation to collect data on a) demographic/socioeconomic characteristics (ethnicity, mother's educational status, monthly household income, child's gender), and b) history of prenatal tobacco smoke exposure (active and/or passive). Information on current feeding practices was periodically collected at 3-month intervals using a separate interviewer-administered questionnaire provided to the mothers and cumulatively used to derive "duration of total breastfeeding". Additionally, child's frequencies of daily toothbrushing and sweet snack intake were recorded using a separate oral health questionnaire provided to primary caregivers at the 24-month dental visit.

Skin and oral examination

Skin examinations for AD diagnosis was performed by physicians/clinical residents at the clinic visits using Hanifin and Rajka criteria ${ }^{14}$. Of the children diagnosed with $\mathrm{AD}$, the disease severity was assessed using the SCORAD (SCORing Atopic Dermatitis) index ${ }^{15}$. Trained clinical residents performed the SCORAD assessments in children at 18- and 36-month clinic visits. If a child had SCORAD scores at both the 18and 36-month clinic visits, the higher of the two SCORAD scores was used in the analysis. Additionally, caregiver-reported history of doctor-diagnosed AD in the first year and findings from skin prick test at 18 months were recorded as described previously ${ }^{8}$.

Dental examinations in children were carried out at 3-year clinic visit by three dentists, who were trained and calibrated to standardize ECC scoring. Examinations were conducted with the knee-to-knee position, using plane surface mouth mirrors aided by tactile inspection, when deemed necessary. Caries detection was performed using modified International Caries Detection and Assessment System (ICDAS) diagnostic criteria ${ }^{16}$, with ICDAS code 1 not recorded due to logistical constraints. No additional detection methods 
or radiographs were used. Inter- and intra-examiner reliability were assessed during the training phase and quantified using the Intraclass Correlation Coefficient (ICC).

Statistical analyses

Statistical analyses were performed using STATA (Version 12). Continuous variables are presented as mean (standard deviation) and median (interquartile range), while categorical variables are presented as $\mathrm{N}(\%)$. The outcome of interest was number of decayed, missing, or filled surfaces (dmfs ). The SCORAD criteria was used to categorize AD severity into: i) moderate-to-severe AD (SCORAD[?]25) and ii) mild AD (SCO$\mathrm{RAD}<25)$ cases. A third group comprising children without AD diagnosis at both clinic visits was used as the reference group (non-AD). Comparison of caries rates across the three groups was done using KruskalWallis analysis, followed by Mann-Whitney test with Bonferroni correction. The distribution of caries was skewed with overdispersion, making negative binomial regression the appropriate statistical technique for multivariable analysis. The estimates were exponentiated to obtain adjusted incidence risk ratios (aIRR) to estimate caries risk in 3-year old children. Potential confounding factors, including ethnicity, maternal education, household income, child's gender, and prenatal tobacco smoke exposure (active/passive) were adjusted for in the analysis. Additionally, robustness of association was further assessed by controlling for postnatal diet (such as duration of breastfeeding, child's daily frequency of sweet snack intake) and oral hygiene factors (such as child's daily frequency of toothbrushing).

\section{Results}

Participant characteristics

Participants' characteristics are presented in Table 1. Out of 837 children who underwent skin examinations, $7.3 \%(61 / 837)$ presented with AD lesions at the time of clinic visits. Amongst 61 children diagnosed with $\mathrm{AD}, 23 \%$ (14/61) presented with moderate-to-severe AD lesions while $77 \%$ (47/61) had mild AD lesions. The mean (SD) SCORAD scores for mild and moderate-to-severe AD cases were 17.2 (4.6) and 37.86 (12.7), respectively.

Of these 837 participants, 181 children $(21.6 \%)$ did not undergo oral examination at 3-years due to logistic/manpower constraints, with no significant differences in socio-demographic characteristics, except for monthly household income, between those who received oral examination vs those who did not (Appendix Table 1). Although the AD severity profile of children who underwent oral examination significantly differed from those who did not, no differences in SCORAD scores were observed for both moderate-to-severe AD and mild $\mathrm{AD}$ groups $(\mathrm{p}>0.05)$. Oral examinations for ECC detection were performed in 656 participants at the 3-year visit. ECC lesions were observed in $85.7 \%(6 / 7), 36.8 \%(14 / 38)$ and $42.8 \%(262 / 611)$ children in moderate-to-severe $\mathrm{AD}$, mild $\mathrm{AD}$ and non-AD groups, respectively. Furthermore, the mean (SD) decayed surfaces in moderate-to-severe, mild and non-AD groups were 5.4 (4.6), 2.2 (4.1) and 2.4 (5.1), respectively. Three examiners performed oral examinations, with mean inter- and intra-examiner reliability scores of 0.80 and 0.80 , respectively (for ICDAS code 2 ) and 0.80 and 0.90 , respectively (for ICDAS codes 3-6).

$\mathrm{AD}$ severity and early childhood caries

A significant difference in number of decayed surfaces across the AD severity groups was observed $(\mathrm{P}=0.04)$. On subgroup analysis after Bonferroni correction, significantly higher decayed surfaces were found in moderate-to-severe $\mathrm{AD}$ group compared to those without $\mathrm{AD}(\mathrm{p}=0.03)$, while no difference was found between mild $\mathrm{AD}$ and the reference group ( $\mathrm{p}=0.62)$ (Table 1). After adjusting for potential confounders (Model-1), children in the moderate-to-severe AD group were at higher risk of ECC (aIRR 2.30 [95\% confidence interval (CI) 1.04-5.06]; $\mathrm{p}=0.03$ ), compared to non-AD group. However, no differences in ECC risk was observed between mild $\mathrm{AD}$ and reference group (aIRR 0.89 [95\% CI 0.47-1.70]; $\mathrm{p}=0.74$ ) (Table 2). Other significant risk factors for ECC included Chinese ethnicity (aIRR 2.91 [95\%CI 1.82-4.66]; p <0.001), Malay ethnicity (aIRR 2.31 [95\%CI 1.37-3.89]; p=0.002) and lower household income level (aIRR 1.94 [95\%CI 1.15-3.26]; $\mathrm{p}=0.01$ ), detailed in Table 2 .

Potential confounding effect of postnatal dietary and oral hygiene factors 
On adjusting for additional postnatal dietary factors such as duration of breastfeeding and frequency of child's daily sweet snack intake (Model-2), children with moderate-to-severe AD also showed a 2-fold increase in ECC risk (aIRR 2.41 [95\%CI 1.08-5.37]; $\mathrm{p}=0.03$ ) compared to non-AD, similar to Model-1 (Table 3). On further inclusion of oral hygiene factors such as child's daily tooth-brushing frequency (Model-3), strength of the association remained robust (aIRR 2.31 [95\%CI 1.06-5.03]; $\mathrm{p}=0.03$ ). For both Models-2 and 3, no association was seen between mild AD and ECC, similar to Model 1 where no dietary/oral hygiene factors were controlled in the regression model.

Comparative evaluation of different diagnostic systems for $\mathrm{AD}$ estimation

Using physician diagnosis as the gold standard, caregiver-report of doctor-diagnosed AD demonstrated high specificity $(86.6 \%)$ and negative predictive value $(\mathrm{NPV}=95.5 \%)$, but low sensitivity $(51.9 \%)$ and positive predictive value $(\mathrm{PPV}=24.8 \%)$, in identifying true $\mathrm{AD}$ cases (Table 4). Single use of SPT performed similar to the caregiver-report of doctor-diagnosed AD with sensitivity, specificity, PPV and NPV of $40.3 \%, 88.2 \%$, $22.6 \%$ and $94.6 \%$, respectively. In contrast, combined criteria of caregiver-reported doctor-diagnosed AD and a positive SPT demonstrated 2-fold higher PPV values (45.4\%), compared to individual criteria, although other parameters such as sensitivity (44.1\%), specificity (96.3\%) and NPV (96.2\%) remained similar.

\section{Discussion}

The present study findings demonstrated that children with moderate-to-severe $\mathrm{AD}$, but not mild $\mathrm{AD}$, to be more susceptible to ECC development, compared to those without the disease. Although complex pathogenic mechanisms of $\mathrm{AD}$ are still evolving, current concepts suggest that defective skin barrier may be a potential driving factor in $\mathrm{AD}$ pathogenesis and not a consequence of the disease ${ }^{17}$. As skin/hair and dental enamel originate from ectoderm, we proposed a sub-clinical structural hypothesis to explain this link based on presence of hair keratin proteins in the mature enamel organic matrix ${ }^{18}$ and association of its mutations with increased caries risk ${ }^{19}$. This was substantiated in a prospective twin study reporting children with infantile eczema to be at 2 times higher risk of developmental enamel defects ${ }^{20}$, which is a well-established risk factor for ECC susceptibility ${ }^{21}$.

Degree/type of skin barrier dysfunction may be one of the major differences between mild and severe forms of the disease, as evidenced by, a) a two-fold increased risk of genetic defects in skin proteins (filaggrin, $F L G$ ) in severe $\mathrm{AD}$ individuals compared to mild $\mathrm{AD}^{22}$, and b) an increased skin permeability dysfunction (transepidermal water loss, TEWL) in severe AD individuals, compared to milder forms of the disease 23. Furthermore, polymorphisms in genes regulating skin barrier function/homeostasis have been linked with tooth developmental anomalies. First, defects in desmosomal proteins such as desmoplakin have been associated with severe AD ${ }^{24}$ and enamel dysplasia ${ }^{25}$, respectively. Second, defects in genes encoding for laminin-332 and type XVII collagen have not only been associated with $\mathrm{AD}^{26}$, but also play a critical role in differentiation of enamel-forming (ameloblasts) cells ${ }^{27}$. Hence, it may be plausible that severity of AD (with corresponding skin barrier defects) may parallel degree of enamel defects and hence risk of caries. Further characterization of enamel proteins in exfoliated deciduous teeth from children with moderate-to-severe AD and non- $\mathrm{AD}$ are ongoing and may elucidate or even confirm the pathogenic pathway proposed in the study.

It can be argued that children with exacerbated $\mathrm{AD}$ symptoms, especially in moderate-to-severe $\mathrm{AD}$, may exhibit compromised compliance and/or attention towards oral hygiene ${ }^{4}$ and thus lead to increased caries susceptibility. Hence, the association between AD severity and ECC was further tested controlling for postnatal dietary (such as duration of breastfeeding, child's daily frequency of sweet snacks) and oral hygiene factors (such as child's brushing frequency) (Table 3). Consistently, similar findings were revealed, with moderate-to-severe AD cases to be at 2-fold higher ECC risk compared to those without AD, substantiating an underlying biological link independent of the dietary-behavioural effect, between moderate-to-severe AD and ECC.

Diagnosis of $\mathrm{AD}$, especially in epidemiological studies, may be subject to potential errors especially in in young children. Conventionally, caregiver-reported history of doctor-diagnosed AD is employed in epidemiological studies ${ }^{9}$, with a reported sensitivity of $70 \%$ and a positive predictive value (PPV) of $87 \%$ in 
children/adolescents ( $<18$ years) in a referral dermatological care setting with high prevalence rates ( $29.5 \%$ ) 10. However, in the present study when the true disease outcome was low $(7.3 \%)$, our results showed lower sensitivity $(51.9 \%)$ and PPV $(24.8 \%)$ in identifying true AD cases (Table 4$)$. These findings indicate that although caregiver-reported criteria may be useful in estimating AD burden in populations with high prevalence rates, its utility in very young children and/or cohorts with low prevalence rates may be compromised. Furthermore, although more than two-thirds of moderate-to-severe AD children in the first 2 years of life demonstrate sensitization to food allergens ${ }^{11}$, low PPV (22.6\%) and sensitivity (40.3\%) of a positive skin prick test suggested that allergic sensitization alone may not be sufficient for AD diagnosis in early-life. In contrast, combining a positive SPT with a caregiver-reported history of doctor-diagnosed AD, as employed in our previous work ${ }^{8}$, resulted in a ${ }^{\sim} 2$-fold higher PPV $(45.4 \%)$ compared to single use of SPT or caregiver-report alone. However, since overall PPV values still remained low (inflated Type I error), its utility in epidemiological studies needs to weighed against the more established diagnostic systems such as Hanifin and Rajka criteria and UK Working Party criteria ${ }^{28}$.

The strengths of this study include the longitudinal study design, use of physician diagnosis in AD estimation, and enumeration of caries at the surface-level (number of surfaces affected), instead of individual-level outcome (yes/no) reported previously ${ }^{8}$. Study limitations include few moderate $(\mathrm{N}=12)$ and severe AD $(\mathrm{N}=2)$ cases available in the cohort. Second, missing data seen due to multiple time-points of data collection reduced the sample size $(\mathrm{N}=581)$. Nevertheless, post-imputation results using multiple imputation by chained equation (creating 40 imputed datasets), demonstrated that exclusion of few missing cases did not affect the results of the study (Appendix Table 2). Third, it was logistically impossible to obtain interand intra-examiner reliability among physicians for AD assessment, although both Hanifin-Rajka criteria

${ }^{29}$ and SCORAD scores ${ }^{30}$ have been shown to exhibit high inter-rater agreement (ICC $>0.80$ ) among physicians/dermatologists. Fourth, severity of AD cases may be underestimated in the current study owing to possible regression of skin lesions before the time of clinic visits and the logistic inability to obtain SCORAD in the first year when the prevalence of the disease is at its peak ${ }^{1}$. Lastly, there may be potential residual confounding as not all confounding factors could be accounted in the analysis due to constraints of sample size.

In conclusion, children with moderate-to-severe atopic dermatitis demonstrated a two-fold increased caries risk at 3 years compared to those without the disease, and early dental referral may be beneficial. Furthermore, diagnostic accuracy of caregiver-reported history of doctor-diagnosed AD, skin prick test, and the combined criteria may be compromised in identifying true $\mathrm{AD}$ cases in certain populations with low $\mathrm{AD}$ prevalence rates.

\section{Acknowledgements}

We thank Dr Chng Chai Kiat for his assistance in securing funding for this study, Dr Pui Ling Chay and Dr Rahul Nair for their help in oral examination and Dr Nisha Subash Chandran Suyien for providing useful comments to revise the manuscript draft. The continuous and skilful help of the home visitors and the clinical team from the National University Hospital and the K.K Women's and Children's Hospital, as well as the database and biostatistics teams, is deeply appreciated.

\section{References}

1. Halkjaer LB, Loland L, Buchvald FF, et al. Development of atopic dermatitis during the first 3 years of life: the Copenhagen prospective study on asthma in childhood cohort study in high-risk children.Arch Dermatol. 2006;142(5):561-566.

2. Silverberg JI, Simpson EL. Associations of childhood eczema severity: a US population-based study. Dermatitis. 2014;25(3):107-114.

3. Xu X, van Galen LS, Koh MJA, et al. Factors influencing quality of life in children with atopic dermatitis and their caregivers: a cross-sectional study. Sci Rep. 2019;9(1):15990. 
4. Silverberg JI, Simpson EL. Association between severe eczema in children and multiple comorbid conditions and increased healthcare utilization. Pediatr Allergy Immunol. 2013;24(5):476-486.

5. Gupta N, Vujicic M, Yarbrough C, Harrison B. Disparities in untreated caries among children and adults in the U.S., 2011-2014. BMC Oral Health. 2018;18(1):30-30.

6. Vos T, Abajobir AA, Abate KH, et al. Global, regional, and national incidence, prevalence, and years lived with disability for 328 diseases and injuries for 195 countries, 1990-2016: a systematic analysis for the Global Burden of Disease Study 2016. The Lancet.2017;390(10100):1211-1259.

7. Tanaka K, Miyake Y, Arakawa M, Sasaki S, Ohya Y. Dental caries and allergic disorders in Japanese children: the Ryukyus Child Health Study.J Asthma. 2008;45(9):795-799.

8. Kalhan TA, Loo EXL, Kalhan AC, et al. Atopic dermatitis and early childhood caries: Results of the GUSTO study. J Allergy Clin Immunol. 2017;139(6):2000-2003.

9. Silverberg JI, Simpson EL. Associations of childhood eczema severity: a US population-based study. Dermatitis : contact, atopic, occupational, drug. 2014;25(3):107-114.

10. Silverberg JI, Patel N, Immaneni S, et al. Assessment of atopic dermatitis using self-report and caregiver report: a multicentre validation study. Br J Dermatol. 2015;173(6):1400-1404.

11. de Benedictis FM, Franceschini F, Hill D, et al. The allergic sensitization in infants with atopic eczema from different countries. Allergy. 2009;64(2):295-303.

12. Silverberg JI, Simpson EL. Association between severe eczema in children and multiple comorbid conditions and increased healthcare utilization. Pediatr Allergy Immunol Off Publ Eur Soc Pediatr Allergy Immunol. 2013;24(5):476-486.

13. Soh SE, Tint MT, Gluckman PD, et al. Cohort profile: Growing Up in Singapore Towards healthy Outcomes (GUSTO) birth cohort study. Int J Epidemiol. 2014;43(5):1401-1409.

14. Hanifin JM. Diagnostic features of atopic dermatitis. Acta Derm Venereol. 1980;92:44-47.

15. The European Task Force on Atopic Dermatitis. Severity Scoring of Atopic Dermatitis: The SCORAD Index. 1993. 1018-8665.

16. Ismail AI, Sohn W, Tellez M, et al. The International Caries Detection and Assessment System (ICDAS): an integrated system for measuring dental caries. Community Dent Oral Epidemiol.2007;35(3):170-178.

17. Han H, Roan F, Ziegler SF. The atopic march: current insights into skin barrier dysfunction and epithelial cell-derived cytokines.Immunol Rev. 2017;278(1):116-130.

18. Duverger O, Beniash E, Morasso MI. Keratins as components of the enamel organic matrix. Matrix Biol. 2016;52-54:260-265.

19. Duverger O, Ohara T, Shaffer JR, et al. Hair keratin mutations in tooth enamel increase dental decay risk. J Clin Invest.2014;124(12):5219-5224.

20. Silva MJ, Kilpatrick NM, Craig JM, et al. Etiology of Hypomineralized Second Primary Molars: A Prospective Twin Study. J Dent Res. 2019;98(1):77-83.

21. Corrêa-Faria P, Paixão-Gonçalves S, Ramos-Jorge ML, Paiva SM, Pordeus IA. Developmental enamel defects are associated with early childhood caries: Case-control study. Int J Paediatr Dent.2020;30(1):11-17.

22. Rodriguez E, Baurecht H, Herberich E, et al. Meta-analysis of filaggrin polymorphisms in eczema and asthma: robust risk factors in atopic disease. J Allergy Clin Immunol. 2009;123(6):1361-1370 e1367.

23. Sugarman JL, Fluhr JW, Fowler AJ, Bruckner T, Diepgen TL, Williams ML. The Objective Severity Assessment of Atopic Dermatitis Score: An Objective Measure Using Permeability Barrier Function and Stra- 
tum Corneum Hydration With Computer-Assisted Estimates for Extent of Disease. Archives of Dermatology. 2003;139(11):1417-1422.

24. Samuelov L, Sarig O, Harmon RM, et al. Desmoglein 1 deficiency results in severe dermatitis, multiple allergies and metabolic wasting. Nat Genet. 2013;45(10):1244-1248.

25. Mahoney MG, Sadowski S, Brennan D, et al. Compound heterozygous desmoplakin mutations result in a phenotype with a combination of myocardial, skin, hair, and enamel abnormalities. J Invest Dermatol. 2010;130(4):968-978.

26. Stemmler S, Parwez Q, Petrasch-Parwez E, Epplen JT, Hoffjan S. Association of variation in the LAMA3 gene, encoding the alpha-chain of laminin 5, with atopic dermatitis in a German case-control cohort.BMC Dermatol. 2014;14:17.

27. Asaka T, Akiyama M, Domon T, et al. Type XVII collagen is a key player in tooth enamel formation. Am J Pathol.2009;174(1):91-100.

28. De D, Kanwar AJ, Handa S. Comparative efficacy of Hanifin and Rajka's criteria and the UK working party's diagnostic criteria in diagnosis of atopic dermatitis in a hospital setting in North India. $J$ Eur Acad Dermatol Venereol. 2006;20(7):853-859.

29. Jøhnke H, Vach W, Norberg LA, Bindslev-Jensen C, Høst A, Andersen KE. A comparison between criteria for diagnosing atopic eczema in infants. Br J Dermatol. 2005;153(2):352-358.

30. Bożek A, Reich A. Assessment of Intra- and Inter-Rater Reliability of Three Methods for Measuring Atopic Dermatitis Severity: EASI, Objective SCORAD, and IGA. Dermatology. 2017;233(1):16-22.

Table 1. Participants' characteristics

\begin{tabular}{|c|c|c|c|c|c|}
\hline Risk Predictors & $\begin{array}{l}\text { AD groups } N \\
(\%)\end{array}$ & $\begin{array}{l}\text { AD groups } N \\
(\%)\end{array}$ & $\begin{array}{l}\text { AD groups } N \\
(\%)\end{array}$ & $\begin{array}{l}\text { Caries }(\mathrm{dmfs}) \text { at } \\
3 \text {-years }(\mathrm{N}=656)\end{array}$ & $\begin{array}{l}\text { Caries }(\mathrm{dmfs}) \text { at } \\
3 \text {-years }(\mathrm{N}=656)\end{array}$ \\
\hline & $\begin{array}{l}\text { Moderate-to- } \\
\text { severe AD } \\
(\mathrm{SCORAD}[?] 25) \\
{[\mathrm{N}=14]}\end{array}$ & $\begin{array}{l}\text { Mild AD } \\
(0<\mathrm{SCO}- \\
\mathrm{RAD}<25) \\
{[\mathrm{N}=47]}\end{array}$ & $\begin{array}{l}\text { Non-AD } \\
{[\mathrm{N}=776]}\end{array}$ & Mean $\pm \mathrm{SD}$ & Median (IQR) \\
\hline Ethnicity & Ethnicity & Ethnicity & Ethnicity & Ethnicity & Ethnicity \\
\hline Chinese & $11(79)$ & $30(64)$ & $441(56.9)$ & $2.5 \pm 5.0$ & $0(0,3)$ \\
\hline Malay & $0(0)$ & $14(30)$ & $197(25.4)$ & $3.3 \pm 9.0$ & $0(0,4)$ \\
\hline Indian & $3(21)$ & $3(6)$ & $137(17.7)$ & $1.0 \pm 1.9$ & $0(0,1.7)$ \\
\hline Mother's & Mother's & Mother's & Mother's & Mother's & Mother's \\
\hline education & education & education & education & education & education \\
\hline $\begin{array}{l}\text { Pre-university } \\
\& \text { above }\end{array}$ & $13(93)$ & $35(74)$ & $457(59.4)$ & $1.9 \pm 3.5$ & $0(0,2)$ \\
\hline $\begin{array}{l}\text { Secondary \& } \\
\text { below }\end{array}$ & $1(7)$ & $12(26)$ & $312(40.6)$ & $3.4 \pm 8.5$ & $0(0,4)$ \\
\hline Monthly & Monthly & Monthly & Monthly & Monthly & Monthly \\
\hline $\begin{array}{l}\text { household } \\
\text { income }\end{array}$ & $\begin{array}{l}\text { household } \\
\text { income }\end{array}$ & $\begin{array}{l}\text { household } \\
\text { income }\end{array}$ & $\begin{array}{l}\text { household } \\
\text { income }\end{array}$ & $\begin{array}{l}\text { household } \\
\text { income }\end{array}$ & $\begin{array}{l}\text { household } \\
\text { income }\end{array}$ \\
\hline 0-1999 SGD & $1(8)$ & $8(18)$ & $108(14.8)$ & $3.5 \pm 6.1$ & $1(0,5)$ \\
\hline $\begin{array}{l}2000-3999 \\
\text { SGD }\end{array}$ & $1(8)$ & $14(33)$ & $213(29.1)$ & $2.8 \pm 6.4$ & $0(0,2)$ \\
\hline $\begin{array}{l}4000-5999 \\
\text { SGD }\end{array}$ & $4(30)$ & $6(14)$ & $188(25.7)$ & $2.0 \pm 3.5$ & $0(0,3)$ \\
\hline$>6000$ SGD & $7(54)$ & $15(35)$ & $222(30.4)$ & $1.8 \pm 3.5$ & $0(0,2)$ \\
\hline
\end{tabular}




\begin{tabular}{|c|c|c|c|c|c|}
\hline Risk Predictors & $\begin{array}{l}\mathrm{AD} \text { groups } \mathrm{N} \\
(\%)\end{array}$ & $\begin{array}{l}\text { AD groups } N \\
(\%)\end{array}$ & $\begin{array}{l}\text { AD groups } N \\
(\%)\end{array}$ & $\begin{array}{l}\text { Caries }(\mathrm{dmfs}) \text { at } \\
3 \text {-years }(\mathrm{N}=656)\end{array}$ & $\begin{array}{l}\text { Caries }(\mathrm{dmfs}) \text { at } \\
3 \text {-years }(\mathrm{N}=656)\end{array}$ \\
\hline $\begin{array}{l}\text { Prenatal } \\
\text { tobacco smoke } \\
\text { exposure }\end{array}$ & $\begin{array}{l}\text { Prenatal } \\
\text { tobacco smoke } \\
\text { exposure }\end{array}$ & $\begin{array}{l}\text { Prenatal } \\
\text { tobacco smoke } \\
\text { exposure }\end{array}$ & $\begin{array}{l}\text { Prenatal } \\
\text { tobacco smoke } \\
\text { exposure }\end{array}$ & $\begin{array}{l}\text { Prenatal } \\
\text { tobacco smoke } \\
\text { exposure }\end{array}$ & $\begin{array}{l}\text { Prenatal } \\
\text { tobacco smoke } \\
\text { exposure }\end{array}$ \\
\hline Yes & $3(21)$ & $13(29)$ & $277(37.4)$ & $3.0 \pm 8.0$ & $0(0,3)$ \\
\hline No & $11(79)$ & $32(71)$ & $463(62.6)$ & $2.1 \pm 4.8$ & $0(0,2)$ \\
\hline Child's gender & Child's gender & Child's gender & Child's gender & Child's gender & Child's gender \\
\hline Female & $8(57)$ & $27(57)$ & $363(46.8)$ & $2.6 \pm 7.4$ & $0(0,2)$ \\
\hline Male & $6(43)$ & $20(43)$ & $413(53.2)$ & $2.3 \pm 4.6$ & $0(0,3)$ \\
\hline Child's daily & Child's daily & Child's daily & Child's daily & Child's daily & Child's daily \\
\hline frequency of & frequency of & frequency of & frequency of & frequency of & frequency of \\
\hline intake by & intake by & intake by & intake by & intake by & intake by \\
\hline 2-years & 2-years & 2-years & 2-years & 2-years & 2-years \\
\hline Twice or more & $11(78.6)$ & $20(50)$ & $298(43.7)$ & $3.0 \pm 7.8$ & $0(0,4)$ \\
\hline Once or none & $3(21.4)$ & $20(50)$ & $384(56.3)$ & $2.2 \pm 4.6$ & $0(0,2)$ \\
\hline Child's daily & Child's daily & Child's daily & Child's daily & Child's daily & Child's daily \\
\hline frequency of & frequency of & frequency of & frequency of & frequency of & frequency of \\
\hline $\begin{array}{l}\text { tooth brushing } \\
\text { by 2-years }\end{array}$ & $\begin{array}{l}\text { tooth brushing } \\
\text { by 2-years }\end{array}$ & $\begin{array}{l}\text { tooth brushing } \\
\text { by 2-years }\end{array}$ & $\begin{array}{l}\text { tooth brushing } \\
\text { by 2-years }\end{array}$ & $\begin{array}{l}\text { tooth brushing } \\
\text { by 2-years }\end{array}$ & $\begin{array}{l}\text { tooth brushing } \\
\text { by 2-years }\end{array}$ \\
\hline Twice or more & $8(57.1)$ & $23(57.5)$ & $359(52.6)$ & $2.8 \pm 7.3$ & $0(0,2)$ \\
\hline Once or none & $6(42.9)$ & $17(42.5)$ & $324(47.4)$ & $2.3 \pm 4.9$ & $0(0,3)$ \\
\hline Duration of & Duration of & Duration of & Duration of & & \\
\hline $\begin{array}{l}\text { breastfeeding } \\
\text { (in months) }\end{array}$ & $\begin{array}{l}\text { breastfeeding } \\
\text { (in months) }\end{array}$ & $\begin{array}{l}\text { breastfeeding } \\
\text { (in months) }\end{array}$ & $\begin{array}{l}\text { breastfeeding } \\
\text { (in months) }\end{array}$ & & \\
\hline Mean $\pm \mathrm{SD}$ & $8.6 \pm 10.3$ & $7.1 \pm 8.8$ & $5.9 \pm 7.9$ & & \\
\hline $\begin{array}{l}\text { SCORAD } \\
\text { scores }^{a}\end{array}$ & $\begin{array}{l}\text { SCORAD } \\
\text { scores }^{a}\end{array}$ & $\begin{array}{l}\text { SCORAD } \\
\text { scores }^{a}\end{array}$ & $\begin{array}{l}\text { SCORAD } \\
\text { scores }^{a}\end{array}$ & & \\
\hline $\begin{array}{l}\text { scores }^{a} \\
\text { Mean } \pm \text { SD }\end{array}$ & $\begin{array}{l}\text { scores }^{a} \\
37.8 \pm 12.7\end{array}$ & $\begin{array}{l}\text { scores }^{a} \\
17.2 \pm 4.6\end{array}$ & $\begin{array}{l}\text { scores }^{0} \\
\text { N.A. }\end{array}$ & & \\
\hline Caries (dmfs) & Caries (dmfs) & Caries (dmfs) & Caries (dmfs) & & \\
\hline at 3-years & at 3-years & at 3-years & at 3-years & & \\
\hline Mean \pm SD & $5.4 \pm 4.6^{b}$ & $2.2 \pm 4.1$ & $2.4 \pm 5.1$ & & \\
\hline Median (IQR) & $7(1$ to 10$)$ & $0(0$ to 3.2$)$ & $0(0$ to 2$)$ & & \\
\hline
\end{tabular}

AD, atopic dermatitis; SCORAD, SCORing Atopic Dermatitis; dmfs, decayed missing and filled surfaces; $S G D$, Singapore dollars; SD, standard deviation; IQR, interquartile range.

${ }^{a}$ recorded at 18 mo and/or 36 mo clinic visit; ${ }^{b} P<0.05$, Mann-Whitney test followed by Bonferroni correction.

Table 2. Association between AD severity (by 3 years) and caries risk (at 3 years)

\begin{tabular}{lllr}
\hline CHARACTERISTICS & CHARACTERISTICS & Outcome: Caries risk at 3 years (dmfs) & Outcome: \\
\hline \multirow{3}{*}{ AD severity } & & $\mathbf{N}$ & Crude IR \\
& Moderate-to-Severe AD & 7 & $\mathbf{2 . 2 2}(\mathbf{1 . 2 0}$ \\
Ethnicity & Mild AD & 38 & $0.91(0.49-1$ \\
& Non-AD & 611 & 1 \\
& Chinese & 408 & $2.48(1.69-3$ \\
Gender & Malay & 193 & $3.21(1.93-5$ \\
& Indian & 120 & 1 \\
& Female & 347 & $1.12(0.79-1$
\end{tabular}




\begin{tabular}{|c|c|c|c|}
\hline CHARACTERISTICS & CHARACTERISTICS & Outcome: Caries risk at 3 years (dmfs) & Outcome: \\
\hline & Male & 374 & 1 \\
\hline \multirow{2}{*}{ Maternal educational levels } & Secondary \& below & 289 & $1.76(1.26-2$ \\
\hline & Pre-university \& above & 426 & 1 \\
\hline \multirow[t]{4}{*}{ Monthly household income } & 0-1999 SGD & 108 & $1.86(1.21$ \\
\hline & 2000-3999 SGD & 201 & $1.49(0.9$ \\
\hline & 4000-5999 SGD & 169 & $1.06(0.73-1$ \\
\hline & [?]6000 SGD & 194 & 1 \\
\hline \multirow{2}{*}{ Prenatal tobacco smoke exposure } & Yes & 261 & $1.41(0.97-$ \\
\hline & No & 423 & 1 \\
\hline
\end{tabular}

IRR, incidence risk ratio; CI, confidence interval, AD, atopic dermatitis; SGD, Singapore dollars; dmfs, decayed missing and filled surfaces.

a aIRR, adjusted incidence risk ratio; adjusted for ethnicity, gender, maternal educational levels, monthly household income, prenatal tobacco smoke exposure.

Table 3. Effect of postnatal dietary and oral hygiene factors on the association between AD severity and caries risk

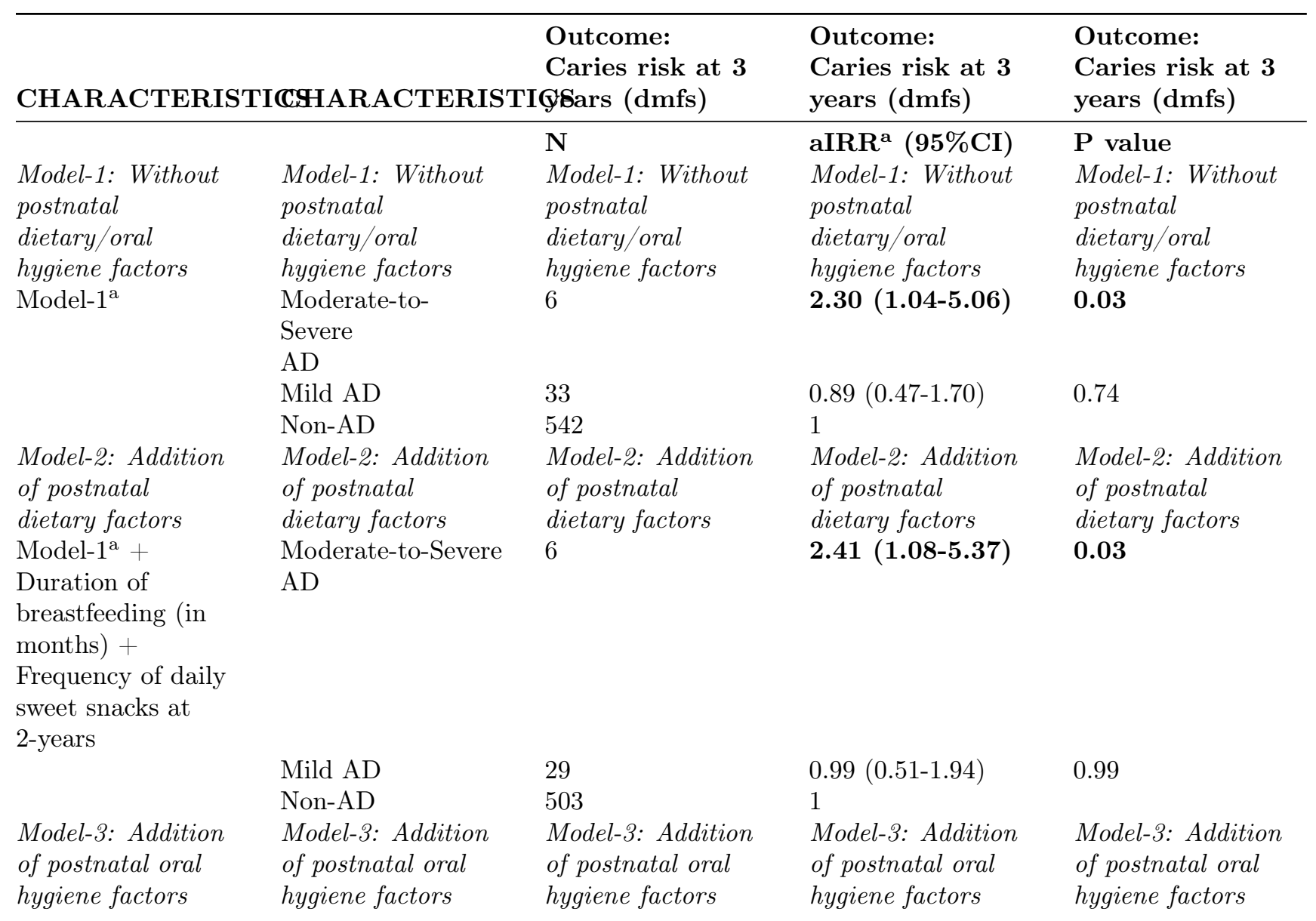




\begin{tabular}{|c|c|c|c|c|}
\hline \multicolumn{3}{|c|}{$\begin{array}{cc} & \text { Outcome: } \\
\text { Caries risk at } 3 \\
\text { CHARACTERISTICYHARACTERISTIGSars (dmfs) }\end{array}$} & \multirow{2}{*}{$\begin{array}{l}\text { Outcome: } \\
\text { Caries risk at } 3 \\
\text { years }(\mathrm{dmfs}) \\
2.31(1.06-5.03)\end{array}$} & \multirow{2}{*}{$\begin{array}{l}\text { Outcome: } \\
\text { Caries risk at } 3 \\
\text { years (dmfs) } \\
0.03\end{array}$} \\
\hline \multirow{3}{*}{$\begin{array}{l}\text { Model-1 } 1^{\mathrm{a}}+ \\
\text { Duration of } \\
\text { breastfeeding (in } \\
\text { months) }+ \\
\text { Frequency of daily } \\
\text { sweet snacks at } \\
\text { 2-years + Child's } \\
\text { daily brushing } \\
\text { frequency at 2-years }\end{array}$} & $\begin{array}{l}\text { Moderate-to-Severe } \\
\text { AD }\end{array}$ & 6 & & \\
\hline & Mild AD & 29 & $0.99(0.51-1.92)$ & 0.99 \\
\hline & Non-AD & 503 & 1 & \\
\hline
\end{tabular}

IRR, incidence risk ratio; CI, confidence interval, AD, atopic dermatitis; dmfs, decayed missing and filled surfaces.

a aIRR, adjusted incidence risk ratio; adjusted for ethnicity, gender, maternal educational levels, monthly household income, prenatal tobacco smoke exposure.

Table 4. Internal validation of different diagnostic criteria in identifying young children with atopic dermatitis

\begin{tabular}{|c|c|c|c|c|}
\hline & $\begin{array}{l}\text { Outcome: AD } \\
\text { (Physician } \\
\text { diagnosis) }\end{array}$ & $\begin{array}{l}\text { Outcome: AD } \\
\text { (Physician } \\
\text { diagnosis) }\end{array}$ & $\begin{array}{l}\text { Outcome: AD } \\
\text { (Physician } \\
\text { diagnosis) }\end{array}$ & $\begin{array}{l}\text { Outcome: AD } \\
\text { (Physician } \\
\text { diagnosis) }\end{array}$ \\
\hline $\begin{array}{l}\text { Diagnostic } \\
\text { criteria for } \mathrm{AD}\end{array}$ & $\mathrm{PPV}(\%)$ & NPV (\%) & Sensitivity (\%) & Specificity (\%) \\
\hline $\begin{array}{l}\text { Caregiver- } \\
\text { reported } \\
\text { doctor- } \\
\text { diagnosed } \\
\text { AD }\end{array}$ & 24.8 & 95.5 & 51.9 & 86.6 \\
\hline Positive SPT & 22.6 & 94.6 & 40.3 & 88.2 \\
\hline $\begin{array}{l}\text { Caregiver- } \\
\text { reported } \\
\text { doctor- } \\
\text { diagnosed AD } \\
+ \text { Positive } \\
\text { SPT }\end{array}$ & 45.4 & 96.2 & 44.1 & 96.3 \\
\hline
\end{tabular}

AD, atopic dermatitis; SPT, skin prick test; PPV, positive predictive value; $N P V$, negative predictive value

Figure 1. Flowchart for the study design

Legend. Abbreviations: AD, atopic dermatitis; SCORAD, SCORing Atopic Dermatitis

\section{Hosted file}

Figure 1.pdf available at https://authorea.com/users/382053/articles/498009-clinicalseverity-of-atopic-dermatitis-is-associated-with-dental-caries-risk-in-3-year-old-

children 